\title{
Research Paper: Analgesic Effect of Bumetanide on Neuropathic Pain in Patients With Spinal Cord Injury
}

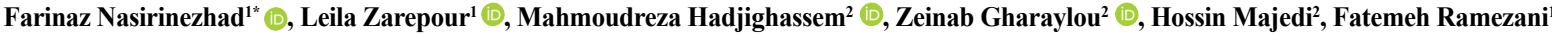

1. Department of Physiology, Physiology Research Center, Iran University of Medical Sciences, Tehran, Iran.

2. Brain and Spinal cord Injury Research Center, Neuroscience Institute, Tehran University of Medical Sciences, Tehran, Iran

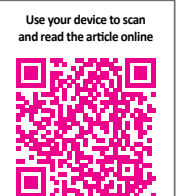

Citation: Nasirinezhad, F., Zarepour, L., Hadjighassem, M., Gharaylou, Z., Majedi, H., \& Ramezani, F. Analgesic Effect of Bumetanide on Neuropathic Pain in Patients With Spinal Cord Injury. Basic and Clinical Neuroscience, 12(3), 409-420. http:// dx.doi.org/10.32598/bcn.12.3.2049.1

http://dx.doi.org/10.32598/ben.12.3.2049.1

Article info:

Received: 22 Sep 2019

First Revision: 15 Oct 2019

Accepted: 21 Jan 2020

Available Online: 01 May 2021

Keywords:

Bumetanide, Na-K-Cl

Cotransporter-1 (NKCC1),

K-Cl Cotransporter-2 (KCC2),

Neuropathic pain, Spinal cord injury, GammaAminobutyric Acid (GABA)

\section{$\underline{\text { A B S T RA C T }}$}

Introduction: The current study evaluated the analgesic effects of bumetanide as an adjunctive in the management of neuropathic pain following Spinal Cord Injury (SCI). The peripheral expression of $\mathrm{Na}-\mathrm{K}-\mathrm{Cl}$ Cotransporter-1 (NKCCl) and $\mathrm{K}$ - $\mathrm{Cl}$ Cotransporter-2 (KCC2) genes in polymorphonuclear lymphocytes (PMLs) was assessed as a possible biomarker indicating central mechanisms underlying the observed response.

Methods: Through an open-label, single-arm, pilot trial of bumetanide $(2 \mathrm{mg} / \mathrm{d})$, an add-on treatment was conducted on 14 SCI patients for 19 weeks. This study consisted of 3 phases: pre-treatment ( 1 month), titration ( 3 weeks), and active treatment (4 months). Ultimately, 9 patients completed the study. The primary outcome variables were the endpoint pain score using the Numeric Rating Scale (NRS), and also the short-form of the McGill pain questionnaire. Secondary endpoints included the short-form of the health survey that assesses the quality of life. Blood samples were collected and used for determining the expression of $\mathrm{NKCC1}$ and $\mathrm{KCC} 2$ genes in transcription and translation levels.

Results: Bumetanide treatment significantly decreased average pain intensity according to the $\mathrm{NRS}$ and the short-form of the McGill pain questionnaire scores. Baseline expression of KCC2 protein was low between groups and increased significantly following treatment $(\mathrm{P}<0.05)$. In the current study, pain improvement was accompanied by the greater mean change from the baseline (improvement) for the overall quality of life.

Conclusion: These data highlighted the analgesic effect of bumetanide on neuropathic pain and indicated the potential role of the upregulation of $\mathrm{KCC} 2$ protein and involvement of GABAergic disinhibition in producing neuropathic pain. 


\section{Highlights}

- Spinal cord comprises the most critical neural pathways.

- Small-sized perturbations could emerge into a broad unpredictable array of pathophysiological events.

- One consequence of these CNS-confined injuries is a pain called central neuropathic pain.

- Loss of inhibitory neuronal cells or inappropriate blockade of the current inhibition in pain is the direct subsequent of the injury.

- NKCC1 blocker might attenuate associated pain scores and improve quality of life.

\section{Plain Language Summary}

The spinal cord contains the most critical neural pathways for multidirectional transportation. A small-sized could emerge into a broad unpredictable range of pathophysiological events. Thus, any consequence of these CNS-confined injuries may lead to a pain called central neuropathic pain. SCI-induced disinhibiting causes abnormal interactions between the sympathetic and sensory pathways and facilitates pain information transition to the perception centers of the cerebrum - also, peripheral nerve injury-induced increases in $\mathrm{NKCCl}$ activity within dorsal root ganglia. Thus, the central hypothesis of the present investigation is whether this $\mathrm{NKCC} 1$ blocker might attenuate pain-associated scores and improve quality of life.

\section{Introduction}

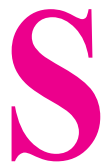

pinal cord comprises the most critical neural pathways for the multidirectional transportation of various sensations and commands in a precisely computed and condense framework (Arle, Iftimia, Shils, Mei \& Carlson, 2019; Ben-Ari, 2017). Accordingly, even small-sized perturbations could emerge into a broad unpredictable array of pathophysiological events within a temporally inconsistent scope (Florence Keller, Beggs, Salter \& De Koninck, 2007). One prominent outcome of these CNS-confined injuries is a kind of pain called the central Neuropathic Pain (NP) that frequently leads to divergent neurological manifestations (burning, stabbing, and pain that is similar in quality to electric shock) (Watson \& Sandroni, 2016) and neuropsychological complications (anxiety, depression, difficulties with attention, concentration, memory, problem solving and abstract reasoning) (Murray et al., 2007). Spinal Cord Injury (SCI) refers to an injury to the spinal cord associated with varying degrees of sensory and or motor deficits and paralysis (Kraus, Franti, Riggins, Richards \& Borhani, 1975). Compared to sexual disabilities and movement limitations, this pain category could affect the quality of life and social participation more severely (Vranken, 2013).
Loss of inhibitory neuronal cells or inappropriate blockade of the pain suppression hierarchy is the direct consequence of the injury or indirect response to the remodeling of the structure of the spinal cord transmitting pathways (Zholudeva et al., 2018). SCI-induced disinhibition causes abnormal interactions between the sympathetic and sensory pathways and facilitates pain information transition to the perception centers of the cerebrum. These conditions lead to hyperexcitability and oversensitivity (Kramer et al., 2017; Vranken, 2013). Gamma-Aminobutyric Acid (GABA) plays a vital central role in the pain perception matrix. In physiological conditions, adult neurons have low intracellular $\mathrm{Cl}$ - levels underlying the inhibitory role of GABA (Schulte, Wierenga \& Bruining, 2018).

In contrast, in a wide range of pathological conditions, including spinal cord lesions, chronic pain, brain trauma, autism, and various types of epilepsies, neurons have a high level of intracellular $\mathrm{Cl}$ - which excites GABA actions (Gwak \& Hulsebosch, 2011). The expression ratios of two electroneutral cotransporters, i.e., $\mathrm{Na}-\mathrm{K}-\mathrm{Cl}-$ Cotransporter-1 (NKCC1) that imports chloride ions into the cells and export potassium and sodium out of the many cell types and K-Cl-cotransporter-2, which exports chloride out of the cells, are determining factors in shaping the GABA polarity (Ben-Ari, 2017). The high concentration of chloride due to up-regulation of $\mathrm{NKCC} 1$ or down-regulation of $\mathrm{KCC} 2$ makes the GABA an excitatory and triggering agent for NP (Hasbargen et 
al., 2010; Mòdol, Cobianchi \& Navarro, 2014). Peripheral nerve injury increases NKCC1 activity within the dorsal root ganglia, ventral posterior thalamic nucleus, and the primary sensory cortical regions that play a role in the allodynia and hyperalgesia (Mòdol et al., 2015).

Drugs targeting these transporters and restoring GABAergic inhibitory responses might be a novel therapeutic strategy for alleviating neuropathic pain. Bumetanide is a sulfonamide-derived diuretic that, as a specific NKCC1 inhibitor, might have an analgesic effect. Intrathecal injection of bumetanide has increased withdrawal latency tension, reduced thermal hyperalgesia, and attenuated allodynia and hyperalgesia in pain characteristics induced by paclitaxel in one rat model (He, Xu, Huang \& Gong, 2014). Another study showed that bumetanide could attenuate mechanical allodynia in the SCI model in rats (Chen et al., 2014).

Considering potentials of bumetanide in restoring central and peripheral inhibitory arm of balance and also the refractoriness of NP following spinal cord injury (around $30 \%$ of the patients report a $50 \%$ decline in their pain symptoms) (Siddall \& Loeser, 2001) to the current pharmacotherapeutic approaches, the present study investigates whether this NKCC1 blocker attenuates pain scores and improves the quality of life.

\section{Methods}

\section{Study design}

This study was conducted as an open-label, single-arm, pilot trial of bumetanide in an add-on protocol for SCI patients with confirmed NP diagnosis. The study protocol was approved by the Ethics Committee of Tehran University of Medical Sciences and registered in the Iranian Registry of Clinical Trials (Code: IRCT201407155368N2). All study patients signed written informed consent. Referred patients to the SCI center of Imam Khomeini Hospital were evaluated based on eligibility criteria. Neuropathic pain diagnosis was made according to the International Association for the Study of Pain (IASP) Special Interest Group on Neuropathic Pain (NeuPSIG) in 2008 (Finnerup et al., 2016). The participants were asked to rate their NP symptoms based on the Short-Form McGill Pain Questionnaire 2 (SF-MPQ-2) (Kachooei et al., 2015) and pain intensity based on the modified Numerical Rating Scale (m-NRS). Moreover, the Iranian Short-Form of health survey (SF-36) was employed to evaluate patients' Quality of Life (QOL).

All study participants were men aged 32-50 years and diagnosed with pain following SCI by a contributing specialist. The included patients had been experiencing moderate-intensity pain for over 3 months (NRS $\geq 4$ ). The exclusion criteria for patients were age over 50 years and with advanced liver, kidney and, heart disease. Patients who participated in other clinical trials in the previous three months were also excluded. Significant neurological or psychological disorders unrelated to NP that can modulate pain perception were the other exclusion factors. The patients were monitored for stabilizing analgesic doses for a month before adding the bumetanide.

\section{Healthy control}

Healthy subjects were assessed according to a checklist for the general medical state, particularly head traumas, seizures, and neuropsychological disorders. The selected ones should not have any medication, alcohol, or substance use. Both groups were matched in age and education scores. Venous blood samples $(10 \mathrm{~mL})$ were collected from patients and 10 age- and sex-matched healthy controls for Peripheral Blood Mononuclear Cells (PBMCs) isolation.

\section{Treatment protocol and outcome variables}

After the baseline assessment, bumetanide tablets were administered orally with an initial dose of $0.5 \mathrm{mg} / \mathrm{d}$ and increased $0.5 \mathrm{mg}$ every week. After 3 weeks of drug titration, a minimum target dose of $2 \mathrm{mg} / \mathrm{d}$ ( $1 \mathrm{mg}$ twice daily) was achieved. At the baseline and after the titration period, the outcome variables and drug safety were assessed at monthly visits.

The primary outcome was measured as a change in mean pain score compared to the baseline on the m-NRS scale. This score indicates pain intensity ranging from 0 "no pain" to 10 , "the worst pain imaginable". The I-SF-MPQ-2 (Kachooei et al., 2015) comprises 4 parts, including continuous (throbbing pain, cramping pain, gnawing pain, aching pain, heavy pain, tender), intermittent (shooting pain, stabbing pain, sharp pain, splitting pain, electric-shock pain, piercing), neuropathic (hot-burning pain, cold-freezing pain, pain caused by light touch, itching, tingling or "pins and needles", numbness), and affective (tiring-exhausting, sickening, fearful, punishing-cruel) subscales. These items were considered primary outcome measurements. The total pain score was calculated by the average score in questions. Moreover, the SF-36 health survey validated in the Iranian population was applied and assessed as secondary outcome measurements for QOL. It measures 8 health-related concepts: physical functioning (10 items), role limitations due to physical problems (4 items), bodily pain ( 2 items), general health perceptions (5 items), vitality (4 items), social functioning ( 2 items), role limitations due to emotional 
problems ( 3 items), and perceived mental health (5 items). Each scale score is rated from 0 to 100 , with a higher number indicating better health status.

\section{Classification of evidence}

This study provides class IV evidence indicating that oral administration of $2 \mathrm{mg} / \mathrm{d}$ bumetanide could be a safe and effective medical option during 4 months of treatment in participants with NP following spinal cord injury.

\section{Quantitative real-time RT-PCR}

Peripheral Blood Mononuclear Cells (PBMC) were isolated from a $5 \mathrm{~mL}$ venous blood sample, which was drawn into an EDTA-containing tube and diluted [1:1] with Phosphate-Buffered Saline (PBS). Then, the layers on top of the Ficoll solution (Ficoll-GE Healthcare, Sigma Aldrich) were centrifuged at $3000 \mathrm{rpm}$ at $18^{\circ} \mathrm{C}$. Afterward, the monocyte layer was collected and washed in PBS twice and centrifuged for 5 minutes at $3000 \mathrm{rpm}$.

Total RNA was extracted from the cells using the TriPure Isolation Reagent Isolation Kit (Roche, Germany) according to the manufacturer's instructions. One microgram of each RNA sample was used for cDNA synthesis for 5 minutes at $85^{\circ} \mathrm{C}$ and 15 minutes' reaction at $37^{\circ} \mathrm{C}$ using the reverse transcriptase (Takara, Japan) in the presence of a random hexamer, Oligo (dT), and RNase inhibitor. The regulation of selected genes was accredited by the quantitative RT-PCR, which was performed in $10 \mu \mathrm{L}$ reaction volumes using SYBRR-Green PCR Master Mix, including $0.5 \mu \mathrm{L}$ reverse-transcribed cDNA, $4 \mu \mathrm{L}$ RNAse free water, $5 \mu \mathrm{L} 5 \mathrm{x}$ primer script plus SYBR and Fluorescein (Takara, Japan), and $0.5 \mu \mathrm{L}$ primers $(10 \mathrm{pmol} / \mu \mathrm{L})$.

Polymerase Chain Reaction (PCR) analysis was conducted using the qRT-PCR detection system (Applied Biosystem, one step, RT-RCP Germany) in special 48well plates under the following conditions: $1 \mathrm{~min}$ at $95^{\circ} \mathrm{C}, 40$ cycles of the $30 \mathrm{~s}$ at $95^{\circ} \mathrm{C}$, and $1 \mathrm{~min}$ at $60^{\circ} \mathrm{C}$. All qRT-PCR steps were performed in triplicate. PCR products were fractionated by $2 \%$ agarose gel electrophoresis, and the bands were visualized by ethidium bromide and photographed with a UVP Imaging System (UVP Company, USA). Hypoxanthine PhosphoribosylTransferase1 (HPRT1) was served as an internal control, and control group samples were used as the reference sample as the proliferation markers. The primers were as follows: KCC2, 5'- GTTCTTCCTGATGTGCTA-3' and 5'-CATAATACCAGGAGCAGA-3'; NKCC1, 5'-TGACTTGAGAGAAGGTGCACAG-3' and
5'-TGTTTGGCTTCATACGACCA-3'; and housekeeping HPRT1, 5'-CCTGGCGTCGTGATTAGTGA-3' and 5'-AAGACGTTCAGTCCTGTCCAT-3'. The outcomes were calculated according to the $\Delta \Delta \mathrm{CT}$ method.

\section{Western blots}

Peripheral monoclonal cells were homogenized in lysis buffer ( $\mathrm{pH}$ 7.4). The extracted proteins were quantified using a Bradford test. For Western blot analysis, $40 \mu \mathrm{g}$ of each protein sample was separated by SDS-Polyacrylamide Gel Electrophoresis (PAGE) on a 10\% gel. After electrophoresis, the proteins were transferred to the polyvinylidene difluoride membranes. The blots were blocked with $5 \%$ non-fat milk in Tris-Buffered Saline containing $0.05 \%$ Tween 20 (TBS-T) for 2 hours at room temperature. Membranes were incubated overnight at $4^{\circ} \mathrm{C}$ with rabbit polyclonal antibody NKCC1 (1:500) (Abcam) and $\operatorname{KCC} 2$ (1:1100) (Abcam) and $\beta$-actin antirabbit polyclonal antibody (1:3000) (Abcam). Following 15 minutes' washes with TBS-T buffer three times, the membranes were incubated for 60 minutes with secondary antibodies at room temperature (1:5000) (Abcam). Immunoreactivity was revealed by ECL (Amersham Biosciences, Freiburg, Germany). Quantitative analysis was carried out by the monomeric band data with the ImageJ software. For the analysis, the background density was subtracted from the $\mathrm{NKCC} 1$ and $\mathrm{KCC} 2$ receptor band density and normalized to $\beta$-actin, which was used as the loading control.

Study analysis

SPSS version 25.0 and GraphPad Prism 7 were used for data analysis. The efficacy analyses were performed by the Intention-to-Treat (ITT) method. ITT population was defined as patients who took at least one dose of bumetanide and provided at least one baseline and one post-baseline efficacy assessment. The efficacy endpoint was the change in the mean monthly pain score on an $\mathrm{m}-\mathrm{NRS}$ and pain items of the I-SF-MPQ-2. The obtained values were expressed as Means \pm Standard Deviation (SD). The endpoints were compared using the linear mixed model, which incorporates all the assessments at baseline and every month during the study.

Nonparametric tests (Mann-Whitney U test, Wilcoxon matched-pairs signed-rank test) were employed for independent and dependent t-test analysis. $\mathrm{P}$ values less than 0.05 considered significant. The Pearson correlation coefficient was calculated for assessing the correlation between the mean change from baseline of 4-month pain scores, QOL assessment, NKCC1, and KCC2 expression. 


\section{Results}

\section{Clinical outcomes}

\section{Efficacy assessment}

Over a four-month experiment period, 14 patients were included in the study. Three patients withdrew from the protocol during the first week of the titration phase because of the adverse effects. The ITT population for the efficacy analysis comprised 11 patients receiving bumetanide up to the second month of treatment, and 9 patients completed 4 months' duration of the study. The baseline demographic and clinical data are summarized in Table 1.

Mixed model analysis showed that NP score decreased significantly $(\mathrm{P}<0.001$; Table 2$)$. There were no statistical differences in continuous, intermittent, and affective parts of I-SF-MPQ-2, but the total score was reduced ( $\mathrm{P}<0.002$; Table 2). Moreover, NRS decreased significantly between the two phases of the trial $(\mathrm{P}<0.04$; Table 2$)$.

The SF-36 was completed by the patients before and after bumetanide treatment. Our data demonstrated the greatest change from baseline (improvement) in total SF-36 score $(\mathrm{P}=0.03)$, general health $(\mathrm{P}=0.03)$, mental health $(\mathrm{P}=0.001)$, role emotional $(\mathrm{P}=0.002)$, and bodily pain $(\mathrm{P}=0.001)$ as $\mathrm{SF}$ 36 subscales (Table 3 ).

\section{Safety assessment}

Drug safety was evaluated based on the category and frequency of the adverse effects reported by the patients. Blood samples were taken and assessed at each visit for chemistry analysis and liver function tests. Also, urine samples were taken. Table 1 presents lab data. Five patients withdrew from the study with their consent: three patients during the titration period and two patients at the end of the second month of study. The dropouts were mainly because of the adverse effects such as intolerance of diuretic effect and the difficulty during evacuation and incontinence. Periodic electrolyte concentration evaluation did not indicate any significant changes during the bumetanide treatment.

\section{NKCC1 and KCC2 mRNAs expression levels}

Baseline comparison analysis of the expression levels of $\mathrm{KCC} 2(\mathrm{P}=0.04)$ and $\mathrm{NKCC} 1(\mathrm{P}=0.01)$ showed a significant difference between healthy controls and patients (Figure 1). Afterward, we evaluated the post-treatment expression of KCC2 and NKCC1 in a 2-month interval (Figure 2). The transcription level of these genes changed significantly following treatment $(\mathrm{KCC} 2$ : $\mathrm{P}=0.04, \mathrm{NKCC} 1$ : $\mathrm{P}=0.001)$.

\section{NKCC1 and KCC2 proteins expression levels}

Western analysis showed a significant difference between protein levels of $\mathrm{NKCC1}$ in patients compared to healthy controls. However, we observed a statistically remarkable low expression level of $\mathrm{KCC} 2$ in patients compared to healthy controls $(\mathrm{P}=0.004)$ (Figure 3 ). Posttreatment evaluation of $\mathrm{NKCC} 1$ and $\mathrm{KCC} 2$ proteins indicated a significant increase in $\mathrm{KCC} 2$ level $(\mathrm{P}=0.02)$ and decrease in NKCC1 level $(\mathrm{P}=0.007)$ protein (Figure 3$)$.

\section{Correlation analyses between variables}

The Pearson correlation coefficients between SF-36 total score significantly changed from baseline with SF36 subscale scores, NP, SF-McGill-Q total score, and KCC2 in the study (Table 4). The correlation coefficients were 0.68 for NRS $(\mathrm{P}=0.021), 0.72$ for mental health $(\mathrm{P}=0.01)$, and 0.82 for bodily pain $(\mathrm{P}=0.002)$ (Table 4$)$. In the current analyses, more pain improvement generally showed a greater mean change from the baseline (improvement) for the overall QOL.

\section{Discussion}

Our study patients suffered from neuropathic pain after SCI. Our results showed that treatment with bumetanide for 4 months significantly reduced their pain intensity based on NRS. In addition, spinal cord injury causes adverse outcomes in various aspects of people's lives that lowers their quality of life (Gurcay, Bal, Eksioglu \& Cakci, 2010). In this study, the SF-36 assessment was applied to examine different aspects of QOL. Our results demonstrated that oral administration of bumetanide could also improve the QOL of SCI patients. The present results also provide some considerable information. First, bumetanide was tolerated by 9 patients. The main side effect was polyuria, an expected consequence that was not tolerated by 5 SCI patients. Second, as an addon treatment to analgesic drugs, bumetanide relieved some NP symptoms. Despite the low concentrations of the bumetanide in the central nervous system following systemic administration (Kaila, Price, Payne, Puskarjov \& Voipio, 2014), recent studies indicate that bumetanide can control some aspects of neurological and neuropsychological disorders such as epilepsy (Gharaylou et al., 2019), schizophrenia (Rahmanzadeh et al., 2017), autism (Jordan James, Gales \& Gales, 2019) and Parkinson disease (Damier, Hammond \& Ben-Ari, 2016). Previous studies have shown that in animal models of spinal cord injury, the use of bumetanide reduces allodynia and hyperalgesia (Kim et al., 2017; Mòdol et al., 2015; Pitcher, Price, Entrena \& Cervero, 2007). 

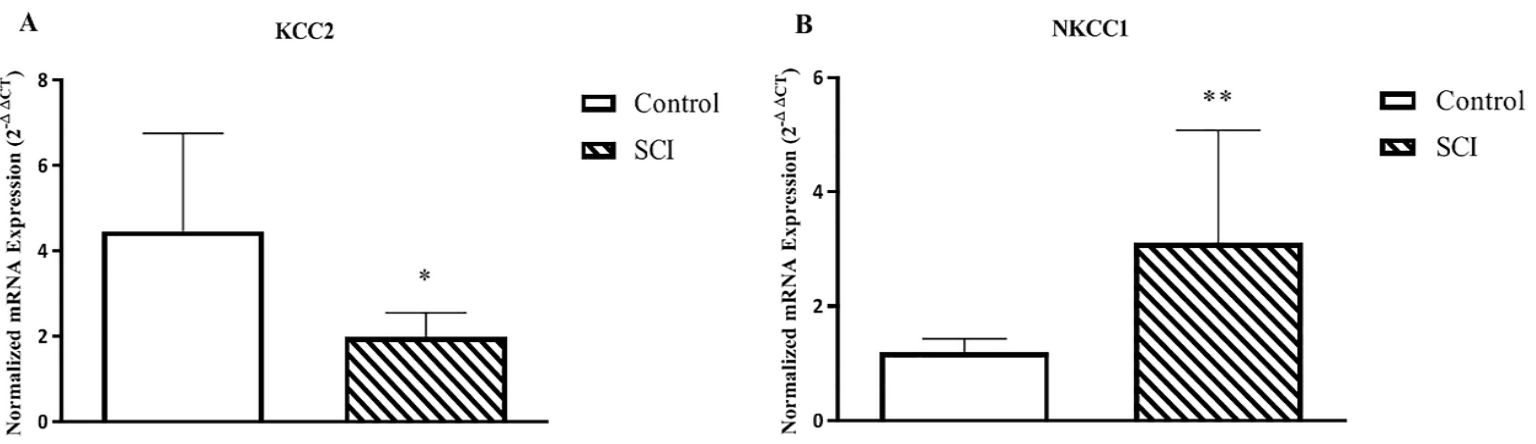

NEUR OSCIENCE

Figure 1. KCC2 and NKCC1 mRNA expression in peripheral blood mononuclear cells between the control healthy and spinal cord injury patients analyzed by quantitative real-time PCR

The normalized gene expression levels were given as the ratio between the mean value of the target gene and the HPRT1 in the patients and control.

Each column represents Mean $\pm \mathrm{SEM}$; ${ }^{\mathrm{P}} \leq 0.05$; ${ }^{* *} \mathrm{P} \leq 0.01$.

In the present study, we identified a significantly low level of the KCC2 protein and mRNA expression and a high level of NKCC1 in the lymphocytes of the patient group compared with the healthy group. As we could not measure the transcription level and proteomic details of the living human brain, and due to the mirror-like interaction between the CNS and immune system component, we measured the peripheral expression of these transporters. The brain and the immune system use a common biochemical language, where scientists can track changes in the central nervous system in the immune system. There are some reports of the correlation between mental health and chloride transporters expression in human peripheral blood mononuclear cells (Bhandage et al., 2015), indicating the interaction between the CNS and immune system. We found that compared to healthy subjects, SCI patients expressed lower levels of KCC2 proteins and mRNA in their peripheral blood. One animal study revealed lower KCC2 expression in the SCI model during neuropathic pain development (Campbell \& Meyer, 2006). We noticed a significant increase in KCC2 protein expression level following bumetanide treatment.

The current results also showed that bumetanide therapy decreased $\mathrm{NKCC} 1$ gene expression in SCI patients, which is in line with the previous study results (Mòdol et al., 2014). Consistent with this study, the results of another study demonstrated that bumetanide phosphorylates NKCC1 and minimizes downregulation of KCC2, and reduces neuropathic pain after peripheral nerve injury (Mòdol et al., 2014). Studies have shown that increased NKCC1 expression and reduced KCC2 expression have a prominent role in neuropathic pain (Hasbargen et al., 2010), who reported a reduction in neuropathic pain after KCC2 recovery (Sánchez-Brualla et al., 2018).
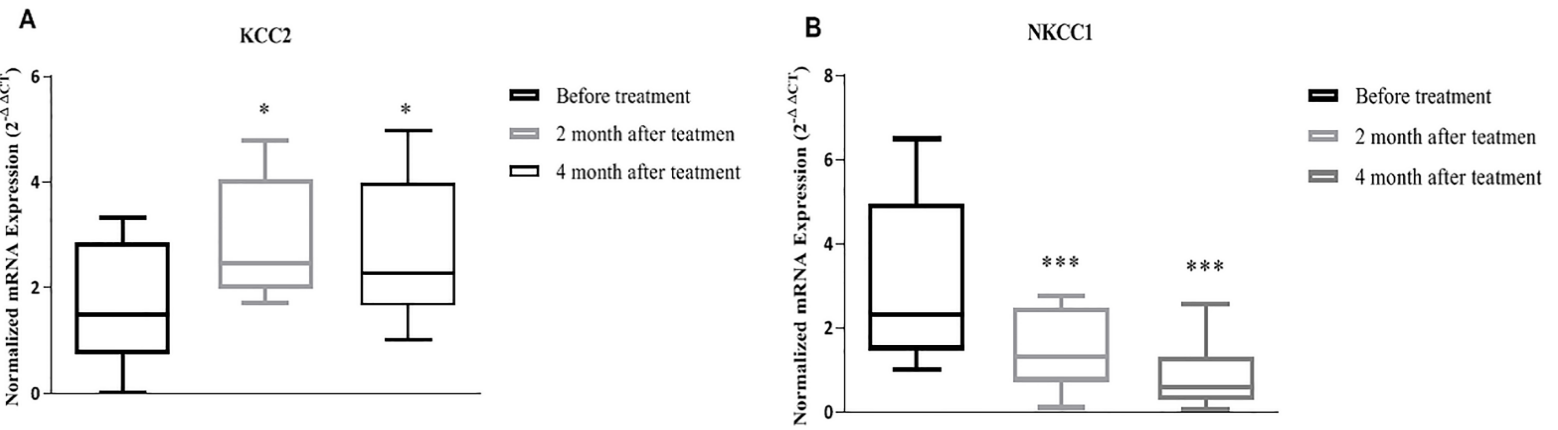

NEUR SCIENCE

Figure 2. KCC2 and NKCC1 mRNA expression in the peripheral blood mononuclear cells before, two, and four months after bumetanide treatment showing a significant change in KCC2 (P $\leq 0.05)$ and NKCC1 $(\mathrm{P} \leq 001)$

Data were analyzed by nonparametric repeated measure ANOVA (Friedman's test) with Dunn's multiple comparisons test; (A) KCC2 expression; (B) NKCC1 expression. Data from each group are presented as box and whisker plot by the Tukey test. 
Table 1. Demographic and baseline clinical data of the patients with neuropathic pain following spinal cord injury

\begin{tabular}{|c|c|c|c|c|c|c|c|c|c|}
\hline \multirow{2}{*}{$\begin{array}{l}\text { Age Range } \\
\text { (Y) }\end{array}$} & \multirow{2}{*}{$\begin{array}{c}\text { Subject } \\
\text { No. / } \\
\text { Gender }\end{array}$} & \multirow{2}{*}{$\mathrm{TFI}^{1}$} & \multirow{2}{*}{$\begin{array}{l}\text { Level and } \\
\text { /Kind of } \\
\text { Injury }\end{array}$} & \multirow{2}{*}{$\begin{array}{l}\text { Symptom Character- } \\
\text { istics }\end{array}$} & \multirow{2}{*}{$\begin{array}{l}\text { Background Medi- } \\
\text { cations }\end{array}$} & \multicolumn{4}{|c|}{ Blood Electrolyte Concentration } \\
\hline & & & & & & $\mathbf{K}^{+}$ & $\mathrm{Na}^{+}$ & $\mathrm{Ca}^{+2}$ & $\mathrm{Mg}^{+2}$ \\
\hline 35 & Male & 4 & $\mathrm{~T} 6 / \mathrm{MVA}^{2}$ & $\begin{array}{l}\text { Burning, shooting, pain } \\
\text { needles, electric shock }\end{array}$ & $\begin{array}{l}\text { Gabapentin, ami- } \\
\text { triptyline, zolpidem, } \\
\text { venlafaxine }\end{array}$ & 3.53 & 137 & 8.4 & 1.82 \\
\hline 33 & Male & 2 & $\mathrm{C} 5 / \mathrm{C6}$ & $\begin{array}{l}\text { Burning, shooting, pin } \\
\text { \& needles, electric } \\
\text { shock, coldness }\end{array}$ & $\begin{array}{l}\text { Pregabalin, amitripty- } \\
\text { line, zolpidem, venla- } \\
\text { faxine, ketorolac }\end{array}$ & 4.51 & 137 & 10.5 & 2.05 \\
\hline 34 & Male & 3 & L1/ MVA & Burning, shooting & $\begin{array}{l}\text { Gabapentin, amitrip- } \\
\text { tyline }\end{array}$ & 3.6 & 136 & 8.9 & 2 \\
\hline 32 & Male & 4 & T6/MVA & $\begin{array}{l}\text { Burning, shooting, pin } \\
\& \text { needles, electric } \\
\text { shock }\end{array}$ & $\begin{array}{l}\text { Gabapentin, venla- } \\
\text { faxine }\end{array}$ & 5 & 142 & 9 & 2.5 \\
\hline 36 & Male & 6 & $\begin{array}{l}\text { T12, L1, } \\
\text { L2/ Fall }\end{array}$ & $\begin{array}{l}\text { Burning, coldness, pin } \\
\text { \& needles }\end{array}$ & $\begin{array}{l}\text { Pregabalin, alpra- } \\
\text { zolam, methadone }\end{array}$ & 3.7 & 143 & 9.6 & 2.1 \\
\hline 40 & Male & 5 & T12/ Fall & $\begin{array}{c}\text { Pin \& needles, electric } \\
\text { shock }\end{array}$ & $\begin{array}{l}\text { Gabapentin, amitrip- } \\
\text { tyline }\end{array}$ & 4.1 & 134 & 10.1 & 2.2 \\
\hline 43 & Male & 3 & $\begin{array}{l}\text { T11, T12/ } \\
\text { Fall }\end{array}$ & $\begin{array}{l}\text { Pin \& needles, numb- } \\
\text { ness, coldness }\end{array}$ & Gabapentin & 4.56 & 141.4 & 10.4 & 2 \\
\hline 50 & Male & 5 & T11/MVA & $\begin{array}{l}\text { Burning, shooting, pin } \\
\text { \& needles, electric } \\
\text { shock }\end{array}$ & $\begin{array}{l}\text { Alprazolam, gaba- } \\
\text { pentin }\end{array}$ & 3.7 & 137 & 8.9 & 2.5 \\
\hline 48 & Male & 3 & L1/MVA & $\begin{array}{l}\text { Burning, shooting, } \\
\text { electric shock }\end{array}$ & $\begin{array}{l}\text { Celecoxib, gaba- } \\
\text { pentin }\end{array}$ & 3.8 & 141 & 9.2 & 2.2 \\
\hline 45 & Male & 10 & $\begin{array}{l}\text { T12, L1/ } \\
\text { Fall }\end{array}$ & Burning, pin \& needles & $\begin{array}{l}\text { Gabapentin, ba- } \\
\text { clofen, amitriptyline, } \\
\text { methadone }\end{array}$ & 4.1 & 140 & 9.4 & 2.3 \\
\hline 47 & Male & 6 & T12/ Fall & $\begin{array}{l}\text { Burning, shooting, } \\
\text { electric shock }\end{array}$ & Gabapentin, baclofen & 4.02 & 140.5 & 9.2 & 2.6 \\
\hline
\end{tabular}

NEUR SCIENCE

TFI: Time From Injury; Time duration after traumatic spinal cord Injury in years; MVA: Motor Vehicle Accidents.

Hypofunction of GABAergic inhibitory tone is an important factor in the enhanced synaptic transmission, which leads to neuronal hyperexcitability in dorsal horn neurons following spinal cord injury (Gwak \& Hulsebosch, 2011). Bumetanide is a highly specific NKCC1 chloride importer antagonist that efficiently restores the low level of intracellular $\mathrm{Cl}$ - leading to resuming GABAergic inhibitory tone and attenuates many disorders in experimental conditions and some clinical trials (Ben-Ari, 2017). Certain studies have demonstrated that blockade of $\mathrm{NKCC1}$ can dramatically reduce allodynia and hyperalgesia. A decrease in the expression of $\mathrm{NKCC} 1$ following the use of bumetanide attenuates many neurological and psychiatric disorders (Ben-Ari, 2017). Moreover, experiments on Down Syndrome mice have shown that the imbalance of NKCC1 and KCC2 expression results in GABAergic stimulatory function that returns to inhibitory GABAergic function after bumetanide treatment (Deidda et al., 2015). In vitro, bumetanide, as a blocker of $\mathrm{NKCC} 1$, reverses the GABAergic inhibitory response by decreasing intracellular chloride levels, thereby reducing the severity of the electrical and behavioral manifestations of the GABAer- gic stimulus-response in many pathological conditions (Corradini et al., 2018; Doyon, Vinay, Prescott \& De Koninck, 2016). In this regard, certain previous research studies have documented some related evidence, such as a significant increase in $\mathrm{KCC} 2$ expression and decline in NKCC1 expression (Price, Cervero \& de Koninck, 2005) and degrees of relief in neuropathic pain following administration of bumetanide (Cramer et al., 2008).

Some evidence showed that patients with chronic kidney disease and congestive heart failure after intravenous administration of a high dose of bumetanide ( 2 $\mathrm{mg} / \mathrm{h}$ ), showed symptoms of neuropathic pain, like light touch tenderness, that after drug discontinuation, the symptoms were resolved (Shisler, Austin, Delpire, Sawyer \& Pandey, 2014). These unknown symptoms might be due to the adverse effect of a high dose of bumetanide (Howard \& Dunn, 1997; Shisler et al., 2014). Our study patients received bumetanide at a dose of $2 \mathrm{mg} / \mathrm{d}$ at 12-h intervals. Because bumetanide has approximately 500 -fold more affinity to NKCC1 than KCC2, it inhibits $\mathrm{NKCC} 1$ at a low dose without significant effect on KCC2 (Payne, Rivera, Voipio \& Kaila, 2003). It seems that in our study, bumetanide has been implicated in the 


\section{\begin{tabular}{l|l|l} 
Control & Before Treatment & After 4 Months Treatment
\end{tabular}}

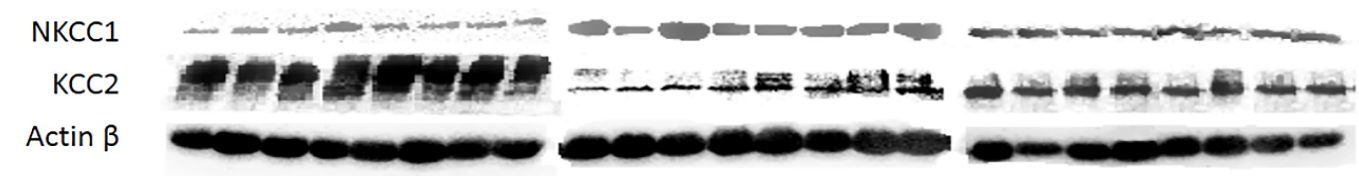

A

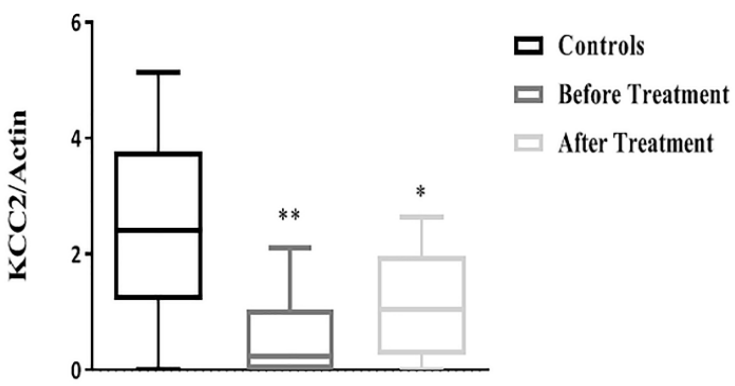

B

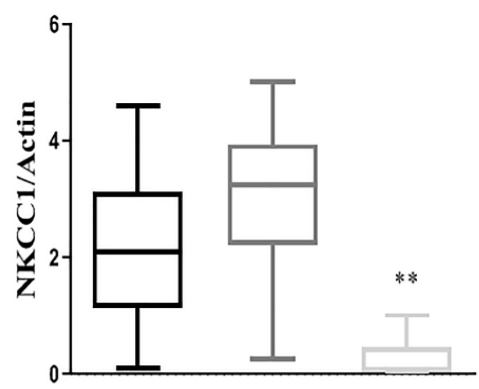

Controls

Before Treatment

- After Treatment

NEUR SCIENCE

Figure 3. KCC2 and NKCC1 protein expression in peripheral blood mononuclear cells analyzed in healthy control subject's versus before treatment with Mann-Whitney test, and before versus after treatment with Wilcoxon matched-pairs signed-rank test, (A) KCC2 expression (B) NKCC1 expression

Expression of KCC2 and NKCC1 was normalized to the beta-actin (KCC2 and NKCC1/Actin); Each column represents Mean $\pm S D ;{ }^{*} \mathrm{P}<0.05$; ${ }^{* *} \mathrm{P}<0.01$.

reduction of NP through the NKCC1 blockade. Considering a 4-week titration period for each individual, we could detect early possible adverse effects because bumetanide is pain-inducing if not prescribed at the appropriate dose (Shisler et al., 2014).
To our knowledge, these observations provide the first evidence of the efficacy of bumetanide on NP and modulation of QOL in SCI patients. Nevertheless, the exact mechanisms by which bumetanide could control chronic neurological symptoms is unclear. It might be assumed that bumetanide reduces the symptoms of pain

Table 2. Comparisons of the SF-McGill-Q and m-NRS responses in patients treated with bumetanide

\begin{tabular}{|c|c|c|c|c|c|c|c|}
\hline \multirow[b]{2}{*}{ Variables } & \multirow{2}{*}{$\begin{array}{l}\text { Number of } \\
\text { Items }\end{array}$} & \multirow[b]{2}{*}{ Item Number } & \multicolumn{3}{|c|}{ Mean $\pm S D$} & \multicolumn{2}{|c|}{ MMA } \\
\hline & & & $\begin{array}{c}\text { Baseline } \\
(\mathrm{n}=11)\end{array}$ & $\begin{array}{l}\text { After } 2 \text { Months } \\
\quad(n=11)\end{array}$ & $\begin{array}{c}\text { After } 4 \\
\text { Months (n=9) }\end{array}$ & $\mathbf{F}$ & $\mathbf{P}$ \\
\hline Continuous & 6 & $1,5,6,8,9,10$ & $7.11 \pm 1.20$ & $6.41 \pm 1.06$ & $5.18 \pm 1.01$ & 3.286 & 0.09 \\
\hline Intermittent & 6 & $2,3,4,11,16,18$ & $5.23 \pm 1.37$ & $4.56 \pm 1.29$ & $4.26 \pm 1.22$ & 2.888 & 0.1 \\
\hline Neuropathic & 6 & $7,17,19,20,21,22$ & $5.68 \pm 2.46$ & $4.17 \pm 1.74$ & $3.25 \pm 1.35$ & 94.237 & 0.001 \\
\hline Affective & 4 & $12,13,14,15$ & $7.12 \pm 0.81$ & $6.62 \pm 0.80$ & $6.3 \pm 0.89$ & 2.331 & 0.14 \\
\hline Total & 22 & & $6.2 \pm 1.83$ & $5.33 \pm 1.68$ & $4.80 \pm 1.67$ & 13.138 & 0.002 \\
\hline NRS Total & & & $7.81 \pm 0.87$ & $5.45 \pm 1.32$ & $4.22 \pm 1.25$ & 3.286 & 0.048 \\
\hline
\end{tabular}

P-values were calculated using Mixed Model Analysis (MMA). Each item in four parts of SF-McGill-Q of continuous, intermittent, neuropathic, and affective is rated based on a 0-10 scale with 0 equal to no pain and 10 equal to the worst pain.

SF-McGill-Q: Short-Form McGill pain Questionnaire; m-NRS: Modified Numerical Rating Scale. 
Table 3. Comparisons of the eight item-scale of health survey (SF-36) for patients before and after treating with bumetanide

\begin{tabular}{|c|c|c|c|}
\hline \multirow{2}{*}{ Variables } & \multicolumn{2}{|c|}{ Mean $\pm S D$} & \multirow{2}{*}{$\mathbf{P}$} \\
\hline & Baseline $(n=9)$ & After 4 Months ( $n=9$ ) & \\
\hline Social functioning & $85.4 \pm 7.82$ & $90.0 \pm 7.38$ & 0.12 \\
\hline Physical functioning & $44.1 \pm 6.84$ & $46.7 \pm 7.14$ & 0.25 \\
\hline Role-physical & $100 \pm 0.01$ & $100 \pm 0.01$ & 0 \\
\hline General health & $40.0 \pm 5.6$ & $44.0 \pm 7.2$ & 0.03 \\
\hline Mental health 26 & $32.7 \pm 9.6$ & $70.5 \pm 15.3$ & 0.001 \\
\hline Vitality & $96.3 \pm 4.8$ & $96.3 \pm 4.8$ & 0 \\
\hline Role emotional & $34.5 \pm 6.5$ & $48.9 \pm 6.6$ & 0.002 \\
\hline Bodily pain & $33.6 \pm 8.8$ & $67.8 \pm 15.4$ & 0.001 \\
\hline Total & $53.7 \pm 28.8$ & $70.5 \pm 21.3$ & 0.03 \\
\hline
\end{tabular}

NEUR:SCIENCE

P-values were calculated using the Wilcoxon matched-pairs signed-rank test; SF-36 containing 36 questions that include 8 subscales.

via resuming GABA-related inhibitory function. Further study using case-control randomized, double-blind designs will elucidate the specificity of this observation.

Our study limitations include the open-label and single-arm study design, involving a relatively small sample size, and the lack of a control group. The gold standard for clinical trials is a well-conducted randomized controlled trial with confirmed blinding throughout the study period. Initially, in the test arm, the patients may withdraw due to adverse effects or lack of tolerance to the drug, especially the diuretic effect of bumetanide, but in the placebo arm, the patients may withdraw due to lack of efficacy. Moreover, the diuretic actions of bumetanide affect the blinding procedure. This trial is viewed as a source of data on safety. Secondly, this is the first clinical trial of bumetanide in human SCI subjects with neuropathic pain. Bumetanide is a loop diuretic, and its safety was not sufficiently assessed in these patients. We need to have sufficient proof to proceed with a large trial and to examine the feasibility of doing such an assessment. We think our study is the first step toward future fully controlled trials.

\section{Conclusion}

The current study points towards the potential therapeutic effects of bumetanide on neuropathic pain in patients with spinal cord injury. Bumetanide acts via an increase in $\mathrm{KCC} 2$ expression and a decline in $\mathrm{NKCC} 1$ expression. Accordingly, bumetanide, as a highly specific NKCC1 chloride importer antagonist, efficiently restores the low level of intracellular $\mathrm{Cl}$ - leading to resuming GABAergic inhibitory tone and attenuates neuropathic pain.

Table 4. The Pearson correlation analysis between SF-36 total score change from baseline with SF-36 subscale scores, NP, SFMcGill-Q total score, and KCC2 That changed significantly in the study

\begin{tabular}{lcccccccc}
\hline \multicolumn{1}{c}{ Variables } & & NP & SF-McGill-Q Total & KCC2 & NRS & Mental Health & Role Emotional & Bodily Pain \\
\hline \multirow{2}{*}{ SF-36 total } & R & 0.186 & 0.146 & -0.042 & $0.681^{*}$ & $0.725^{*}$ & 0.419 & $0.824^{* *}$ \\
& P & 0.583 & 0.669 & 0.903 & 0.021 & 0.012 & 0.199 & 0.002 \\
\hline
\end{tabular}

R-values represent the Pearson correlation coefficient; ${ }^{*}$ Correlation is significant at the 0.05 level (2-tailed); * Correlation is significant at the 0.01 level (2-tailed). 


\section{Ethical Considerations}

\section{Compliance with ethical guidelines}

The study protocol was approved by the Ethics Committee of Tehran University of Medical Sciences and registered in the Iranian Registry of Clinical Trials (Code: IRCT201407155368N2). We certify that all applicable institutional and governmental regulations concerning the ethical use of human volunteers/animals were followed during this research. The datasets generated and or analyzed during the current study are available from the corresponding author on reasonable request.

\section{Funding}

This research did not receive any grant from funding agencies in the public, commercial, or non-profit sectors.

\section{Authors' contributions}

All authors equally contributed to preparing this article.

\section{Conflict of interest}

The authors declared no conflict of interest.

\section{References}

Arle, J. E., Iftimia, N., Shils, J. L., Mei, L., \& Carlson, K. W. (2019). Dynamic computational model of the human spinal cord connectome. Neural Computation, 31(2), 388-416. [DOI:10.1162/ neco_a_01159] [PMID]

Ben-Ari, Y. (2017). NKCC1 chloride importer antagonists attenuate many neurological and psychiatric disorders. Trends in Neurosciences, 40(9), 536-54. [DOI:10.1016/j.tins.2017.07.001] [PMID]

Bhandage, A. K., Hellgren, C., Jin, Z., Olafsson, E. B., Sundström-Poromaa, I., \& Birnir, B. (2015). Expression of GABA receptors subunits in peripheral blood mononuclear cells is gender dependent, altered in pregnancy and modified by mental health. Acta Physiologica, 213(3), 575-85. [DOI:10.1111/ apha.12440] [PMID]

Campbell, J. N., \& Meyer, R. A. (2006). Mechanisms of neuropathic pain. Neuron, 52(1), 77-92. [DOI:10.1016/j.neuron.2006.09.021] [PMID] [PMCID]

Chen, Sh. R., Zhu, L., Chen, H., Wen, L., Laumet, G., \& Pan, H. L. (2014). Increased spinal cord $\mathrm{Na}^{+}-\mathrm{K}^{+}-2 \mathrm{Cl}^{-}$Cotransporter- 1 (NKCC1) activity contributes to impairment of synaptic inhibition in paclitaxel-induced neuropathic pain. Journal of Biological Chemistry, 289(45), 31111-20. [DOI:10.1074/jbc M114.600320] [PMID] [PMCID]
Corradini, I., Focchi, E., Rasile, M., Morini, R., Desiato, G., \& Tomasoni, R., et al. (2018). Maternal immune activation delays excitatory-to-inhibitory gamma-aminobutyric acid switch in offspring. Biological Psychiatry, 83(8), 680-91. [DOI:10.1016/j. biopsych.2017.09.030] [PMID]

Cramer, S. W., Baggott, Ch., Cain, J., Tilghman, J., Allcock, B., \& Miranpuri, G., et al. (2008). The role of cation-dependent chloride transporters in neuropathic pain following spinal cord injury. Molecular Pain, 4, 36. [DOI:10.1186/1744-8069-4 36] [PMID] [PMCID]

Damier, Ph., Hammond, C., \& Ben-Ari, Y. (2016). Bumetanide to treat Parkinson disease: A report of 4 cases. Clinical Neurophar macology, 39(1), 57-9. [DOI:10.1097/WNF.0000000000000114] [PMID]

Deidda, G., Parrini, M., Naskar, Sh., Bozarth, I. F., Contestabile A., \& Cancedda, L. (2015). Reversing excitatory GABA R signaling restores synaptic plasticity and memory in a mouse model of Down syndrome. Nature Medicine, 21(4), 318-26. [DOI:10.1038/nm.3827] [PMID]

Doyon, N., Vinay, L., Prescott, S. A., \& De Koninck, Y. (2016). Chloride regulation: A dynamic equilibrium crucial for synaptic inhibition. Neuron, 89(6), 1157-72. [DOI:10.1016/j.neuron.2016.02.030] [PMID]

Finnerup, N. B., Haroutounian, S., Kamerman, P., Baron, R., Bennett, D. L. H., \& Bouhassira, D., et al. (2016). Neuropathic pain: An updated grading system for research and clinical practice. Pain, 157(8), 1599-606. [DOI:10.1097/j. pain.0000000000000492] [PMID] [PMCID]

Florence Keller, A., Beggs, S., Salter, M. W., \& De Koninck, Y (2007). Transformation of the output of spinal lamina I neurons after nerve injury and microglia stimulation underlying neuropathic pain. Molecular Pain, 3, 27. [DOI:10.1186/17448069-3-27] [PMID] [PMCID]

Gharaylou, Z., Tafakhori, A., Agah, E., Aghamollaii, V., Kebriaeezadeh, A., \& Hadjighassem, M. R. (2019). A preliminary study evaluating the safety and efficacy of bumetanide, an NKCC1 inhibitor, in patients with drug-resistant epilepsy. CNS Drugs, 33(3), 283-91. [DOI:10.1007/s40263-019-00607-5] [PMID]

Gurcay, E., Bal, A., Eksioglu, E., \& Cakci, A. (2010). Quality of life in patients with spinal cord injury. International Journal of Rehabilitation Research, 33(4), 356-8. [DOI:10.1097/ MRR.0b013e328338b034] [PMID]

Gwak, Y. S., \& Hulsebosch, C. E. (2011). GABA and central neuropathic pain following spinal cord injury. Neuropharmacology, 60(5), 799-808. [DOI:10.1016/j.neuropharm.2010.12.030] [PMID] [PMCID]

Hasbargen, T., Ahmed, M. M., Miranpuri, G., Li, L., Kahle, K. T., \& Resnick, D., et al. (2010). Role of NKCC1 and KCC2 in the development of chronic neuropathic pain following spinal cord injury. Annals of the New York Academy of Sciences, 1198(1), 168-72. [DOI:10.1111/j.1749-6632.2010.05462.x] [PMID]

He, Y., Xu, Sh., Huang, J., \& Gong, Q. (2014). Analgesic effect of intrathecal bumetanide is accompanied by changes in spinal sodium-potassium-chloride co-transporter 1 and potassium-chloride co-transporter 2 expression in a rat model of incisional pain. Neural Regeneration Research, 9(10), 1055-62. [DOI:10.4103/1673-5374.133170] [PMID] [PMCID] 
Howard, P. A., \& Dunn, M. I. (1997). Severe musculoskeletal symptoms during continuous infusion of bumetanide. Chest 111(2), 359-64. [DOI:10.1378/chest.111.2.359] [PMID]

Jordan James, B., Gales, M. A., \& Gales, B. J. (2019). Bumetanide for Autism spectrum disorder in children: A review of randomized controlled trials. Annals of Pharmacotherapy, 53(5), 537-44. [DOI:10.1177/1060028018817304] [PMID]

Kachooei, A. R., Ebrahimzadeh, M. H., Erfani-Sayyar, R., Salehi, M., Salimi, E., \& Razi, Sh. (2015). Short Form-McGill Pain Questionnaire-2 (SF-MPQ-2): A cross-cultural adaptation and validation study of the Persian version in patients with knee osteoarthritis. The Archives of Bone and Joint Surgery, 3(1), 45-50. [PMID] [PMCID]

Kaila, K., Price, T. J., Payne, J. A., Puskarjov, M., \& Voipio, J. (2014). Cation-chloride cotransporters in neuronal development, plasticity and disease. Nature Reviews Neuroscience, 15(10), 637-54. [DOI:10.1038/nrn3819] [PMID] [PMCID]

Kim, M. J., Park, Y. H., Yang, K. Y., Ju, J. S., Bae, Y. Ch., \& Han, S. K., et al. (2017). Participation of central GABA receptors in the trigeminal processing of mechanical allodynia in rats. Korean Journal of Physiology \& Pharmacology, 21(1), 65-74. [DOI:10.4196/kjpp.2017.21.1.65] [PMID] [PMCID]

Kramer, J. L. K., Minhas, N. K., Jutzeler, C. R., Erskine, E. L. K. S. Liu, L. J. W., \& Ramer, M. S. (2017). Neuropathic pain following traumatic spinal cord injury: Models, measurement, and mechanisms. Journal of Neuroscience Research, 95(6), 1295-306. [DOI:10.1002/jnr.23881] [PMID]

Kraus, J. F., Franti, Ch. E., Riggins, R. S., Richards, D., \& Borhani, N. O. (1975). Incidence of traumatic spinal cord lesions. Journal of Chronic Diseases, 28(9), 471-92. [DOI:10.1016/00219681(75)90057-0]

Mòdol, L., Cobianchi, S., \& Navarro, X. (2014). Prevention of NKCC1 phosphorylation avoids downregulation of KCC2 in central sensory pathways and reduces neuropathic pain after peripheral nerve injury. Pain, 155(8), 1577-90. [DOI:10.1016/j. pain.2014.05.004] [PMID]

Mòdol, L., Santos, D., Cobianchi, S., González-Pérez, F., LópezAlvarez, V., \& Navarro, X. (2015). NKCC1 activation is required for myelinated sensory neurons regeneration through JNKdependent pathway. Journal of Neuroscience, 35(19), 7414-27. [DOI:10.1523/JNEUROSCI.4079-14.2015] [PMID] [PMCID]

Murray, R. F., Asghari, A., Egorov, D. D., Rutkowski, S. B., Siddall, P. J., \& Soden, R. J., et al. (2007). Impact of spinal cord injury on self-perceived pre-and postmorbid cognitive, emotional and physical functioning. Spinal Cord, 45(6), 429-36. [DOI:10.1038/sj.sc.3102022] [PMID]

Payne, J. A., Rivera, C., Voipio, J., \& Kaila, K. (2003). Cationchloride co-transporters in neuronal communication, development and trauma. Trends in Neurosciences, 26(4), 199-206. [DOI:10.1016/S0166-2236(03)00068-7]

Pitcher, M. H., Price, T. J., Entrena, J. M., \& Cervero, F. (2007) Spinal NKCC1 blockade inhibits TRPV1-dependent referred allodynia. Molecular Pain, 3, 17. [DOI:10.1186/1744-8069-3-17] [PMID] [PMCID]

Price, T. J., Cervero, F., \& de Koninck, Y. (2005). Role of Cation-Chloride-Cotransporters (CCC) in pain and hyperalgesia. Current Topics in Medicinal Chemistry, 5(6), 547-55. [DOI:10.2174/1568026054367629] [PMID] [PMCID]
Rahmanzadeh, R., Eftekhari, S., Shahbazi, A., Khodaei Ardakani, M. R., Rahmanzade, R., \& Mehrabi, S., et al. (2017). Effect of bumetanide, a selective NKCC1 inhibitor, on hallucinations of schizophrenic patients; a double-blind randomized clinical trial. Schizophrenia Research, 184, 145-6. [DOI:10.1016/j. schres.2016.12.002] [PMID]

Sánchez-Brualla, I., Boulenguez, P., Brocard, C., Liabeuf, S., Viallat-Lieutaud, A., \& Navarro, X., et al. (2018). Activation of 5- $\mathrm{HT}_{2 \mathrm{~A}}$ receptors restores KCC2 function and reduces neuropathic pain after spinal cord injury. Neuroscience, 387, 48-57. [DOI:10.1016/j.neuroscience.2017.08.033] [PMID]

Schulte, J. T., Wierenga, C. J., \& Bruining, H. (2018). Chloride transporters and GABA polarity in developmental, neurological and psychiatric conditions. Neuroscience \& Biobehavioral Reviews, 90, 260-71. [DOI:10.1016/j.neubiorev.2018.05.001] [PMID]

Shisler, D., Austin, T. M., Delpire, E., Sawyer, D. B., \& Pandey, A. K. (2014). Syndrome of severe pain associated with a continuous bumetanide infusion. International Journal of Cardiology, 177(2), E61-2. [DOI:10.1016/j.ijcard.2014.09.160] [PMID] [PMCID]

Siddall, P. J., \& Loeser, J. D. (2001). Pain following spinal cord injury. Spinal Cord, 39(2), 63-73. [DOI:10.1038/sj.sc.3101116] [PMID]

Vranken, J. H. (2013). Neuropathic pain following spinal cord injury. In C. Toth, \& D. E. Moulin (Eds.), Neuropathic Pain: Causes, Management and Understanding (pp. 145-155). Cambridge: Cambridge University Press. [DOI:10.1017/ CBO9781139152211.013]

Watson, J. C., \& Sandroni, P. (2016). Central neuropathic pain syndromes. Mayo Clinic Proceedings, 91(3), 372-85. [DOI:10.1016/j.mayocp.2016.01.017] [PMID]

Zholudeva, L. V., Qiang, L., Marchenko, V., Dougherty, K. J., Sakiyama-Elbert, S. E., \& Lane, M. A. (2018). The neuroplastic and therapeutic potential of spinal interneurons in the injured spinal cord. Trends in Neurosciences, 41(9), 625-39. [DOI:10.1016/j.tins.2018.06.004] [PMID] [PMCID] 
